\title{
CARGA MECÁNICA COMO REGULADOR DE LA OSTEOGÉNESIS EN CÉLULAS MADRE MESENQUIMALES HUMANAS
}

\author{
Rey Cubillos jorge Arturo MSc, ${ }^{1}$ Corredor Pereira Carlos, PhD $^{2}$ \\ Godor Corredor Marcela BSC, ${ }^{3}$ Perdomo Lara SANDRA PhD(C), ${ }^{4}$ \\ BENJAMIN OSPINO MD \\ ${ }^{1}$ Profesor Asociado. Universidad Militar Nueva Granada. \\ ${ }^{2}$ Profesor Titular. Pontificia Universidad Javeriana, Universidad Simón Bolivar. \\ ${ }^{3}$ Joven Investigador Universidad Militar Nueva Granada. \\ ${ }^{4}$ Coinvestigador. Universidad el Bosque y Coinvestigador. Universidad Nacional de Colombia. \\ ${ }^{5}$ Coinvestigador. Hospital Militar Central.
}

\begin{abstract}
Resumen
El papel de la estimulación mecánica en la diferenciación de las células madre mesenquimales humanas (CMMHs) es una alternativa terapéutica para aplicaciones en ingeniería tisular. Este estudio evaluó el efecto de cargas mecánicas sobre la diferenciación de las CMMHs, y los mecanismos celulares que intervienen en el proceso de mecanotransducción. Las $\mathrm{CMMHs}$ se sembraron en frascos de cultivo de $75 \mathrm{~cm}^{2}$ y fueron expuestas a tensión uniaxial de deformación de 500, 1000, 1500 y 2000 micro strains $(\mu \varepsilon)$, con una intensidad de 9 ciclos/minuto por 3 horas durante 4 días consecutivos. Se evaluó la actividad transcripcional de los factores de transcripción Runx 2 y Sox9 y de los genes de Osteocalcina (OC), Colágeno tipo 1 (Col-1) y Fosfatasa Alcalina (ALP). Después de la exposición al estímulo, los marcadores osteogénicos Col-1, OC, y ALP se expresaron temporalmente; y los factores de transcripción Runx 2 y Sox9 disminuyeron la expresión con respecto a las células de grupo control (sin estímulo), sugiriendo que el estímulo mecánico indujo la diferenciación de las células CMMHs a linaje osteoblástico. La identificación de los genes que traducen los estímulos mecánicos en las $\mathrm{CMMHs}$ y modulan la diferenciación osteogénica, tienen proyección directa en medicina regenerativa a través del desarrollo y perfeccionamiento del enfoque de ingeniería de tejidos funcionales.
\end{abstract}

Palabras clave: Células madre mesenquimales, colágeno tipo 1, osteocalcina, diferenciación osteogénica, mecanotransducción.

\section{MECHANICAL STRESS AS OSTEOGENESIS REGULATOR IN HUMAN MESENCHYMAL STEM CELLS}

\begin{abstract}
The role of mechanical stimulation for mesenchymal stem cells (MSCs) differentiation is a therapeutic alternative for applications in tissue engineering. The aim of this study was to evaluate the effect of mechanical strain on the differentiation and cellular mechanisms of mechanotransduction in MSCs. The cells were seeded in $75 \mathrm{~cm}^{2}$ culture flasks and then exposed to uniaxial mechanical tensile strain of 500,1000, 1500 and 2000 micro strains $(\mu \varepsilon), 9$ cycles / minute during 3 hours for 4 consecutive days. Runx 2 and Sox 9 transcription factors andOsteocalcin (OC), Collagen Type 1 (Col-1) and Alkaline Phosphatase (ALP) gene expression was ascertained. After exposure to mechanical strain, osteogenic marker genes Col-1, OC, and ALP were expressed temporally, while Runx2 and Sox9 transcription factors expression decreased, compared with control cells without stimulation, suggesting that mechani-
\end{abstract}

* Correspondencia: Jorge Arturo Rey Cubillos, DDS MSc. Carrera 11 B № 135 A - 08. Interior 5 Apto 201. Bogotá, D.C. Tel. 571 - 6147298 - 3108729347 - Email: reyjorgearturo@gmail.com 
cal stimulus induced differentiation of mesenchymal stem cells into osteoblast lineage. Identification of genes that translate mechanical stimuli in MSCs and modulate osteogenic differentiation hasimportant implications in regenerative medicine as an approach to functional tissue engineering.

Keywords: Mesenchymal stem cells, collagen type 1, osteocalcin, osteogenic differentiation, mechanotransduction.

\title{
CARGA MECÂNICA COMO REGULADOR DA OSTEOGÊNESE EM CÉLULAS-TRONCO MESENQUIMAIS HUMANAS
}

\begin{abstract}
Resumo
O papel da estimulação mecânica na diferenciação das células-tronco mesenquimais humanas (CMMHs) é uma alternativa terapêutica para aplicações em engenharia tissular. Este estudo avaliou o efeito de cargas mecânicas sobre a diferenciação das $\mathrm{CMMHs,} \mathrm{e} \mathrm{os} \mathrm{mecanismos} \mathrm{celulares} \mathrm{que}$ intervém no processo de Mecano-transdução. As $\mathrm{CMMHs}$ foram cultivadas em frascos de cultivo de $75 \mathrm{~cm}^{2}$ e foram expostas a tensão uniaxial de deformação de 500, 1000, 1500 e 2000 micro strains $(\mu \varepsilon)$, com uma intensidade de 9 ciclos/minuto por 3 horas durante 4 dias consecutivos. Foi avaliada a atividade transcricional dos fatores de transcrição Runx2 e Sox9 e dos genes de Osteocalcina (OC), Colágeno tipo 1 (Col-1) e Fosfatase Alcalina (ALP). Depois da exposição ao estímulo, os marcadores osteogênicos Col-1, OC, e ALP foram expressos temporariamente; e os fatores de transcrição Runx2 e Sox9 diminuíram a expressão em comparação com as células do grupo controle (sem estímulo), sugerindo que o estímulo mecânico induziu a diferenciação das células $\mathrm{CMMHs} \mathrm{à}$ linhagem osteoblástica. A identificação dos genes que traduzem os estímulos mecânicos nas $\mathrm{CMMHs}$ e modulam a diferenciação osteogênica, têm projeção direta na medicina regenerativa através do desenvolvimento e aperfeiçoamento do enfoque de engenharia de tecidos funcionais.
\end{abstract}

Palavras chave: Células madre mesenquimais, Colágeno tipo 1, Osteocalcina, Diferenciação osteogênica, Mecano-transdução.

\section{Introducción}

La estimulación mecánica se considera uno de los factores epigenéticos que más influye en la regulación del metabolismo, proliferación, mantenimiento y diferenciación de las células en el tejido óseo. Este proceso conocido como mecano-transducción involucra la activación de moléculas de señalización intracelular $(1,6)$; así como también, la activación de factores de transcripción (7) que modulan la expresión de genes que actúan en diferentes funciones fisiológicas. El estimulo mecánico juega un papel fundamental en la regulación de la homeostasis ósea durante el desarrollo $(8,9)$; su reducción resulta en la pérdida de la masa ósea a través de la inhibición de la formación de hueso y el incremento en la reabsorción $(10,12)$. Sin embargo, la vía precisa de transducción de señales que conecta la carga mecánica con la regulación de la expresión génica, no ha sido completamente elucidada. Los efectos favorables del estímulo mecánico, sobre las estructuras óseas se han demostrado ampliamente en el área clínica. A nivel molecular y celular, las investigaciones han comenzado a esclarecer algunos de los mecanismos que traducen el estímulo mecánico en respuestas bioquímicas $(8,13)$. Estas respuestas a nivel celular y molecular involucran cambios en la expresión de los genes, las cuales son mediadas principalmente por quinasas $(14,15)$. En muchos países se han desarrollado modelos experimentales para estudiar estos procesos en células de cerdo, ratón y conejo. En el presente estudio se trabajó con células humanas para acercar aún más estos resultados con modelos de aplicación clínica sobre pacientes.

En esta investigación, se utilizó un modelo in vitro de carga mecánica que aplica fuerza tensional uniaxial cíclica, esto para evaluar su efecto sobre la modulación en la diferenciación y expresión de genes marcadores de osteogénesis sobre las CMMHs. (Con un modelo novedoso de sistema de aplicación de fuerzas a nivel celular, se construyó un desarrollo tecnológico que se encuentra actualmente en proceso de obtención de patente en Colombia). 


\section{Materiales y métodos}

\section{Cultivo de células madre mesenquimales humanas}

Previo consentimiento informado para el desarrollo de este estudio, se obtuvieron $\mathrm{CMMHs}$ de pacientes adultos sanos, mediante aspirado de médula ósea de la cresta iliaca posterosuperior. Las CMMHs fueron mantenidas a $37^{\circ} \mathrm{C}$ en una atmósfera humidificada de $5 \% \mathrm{CO}_{2}$ en medio DMEM (Dulbecco's Modified Eagle's Medium Low Glucose) (Sigma, St. Louis, MO, USA) suplementado al $20 \%$ con suero fetal bovino (Gibco, USA), 1\% antibiótico-antimicótico (Invitrogen, USA). El recambio de medio de cultivo se realizó cada tercer día, en cada recambio se lavó con 2 mL PBS pH 7.4, eliminando así células madre hematopoyéticas (HSC) y desechos metabólicos para purificar el cultivo. Al completar aproximadamente 90\% de confluencia, las células fueron desprendidas con tripsina al 0,3\% (Invitrogen, USA) en EDTA al $2.5 \%$, durante 3 minutos a $37^{\circ} \mathrm{C}$. Se confirmó el fenotipo de $\mathrm{CMMH}$ por citometría de flujo, utilizando los marcadores CD34-/45-, CD105+/90+/73+ en el equipo FACS Calibur (Beckton Dickinson).

\section{Evaluación del potencial de diferenciación osteogénica}

El potencial de diferenciación osteogénica de las CMMHs se evaluó por determinación de la actividad fosfatasa alcalina (ALP) y Tinción de von Kossa. Para esto, cada pozo con $1 \times 10^{4}$ células $/ \mathrm{cm}^{2}$ se incubó inicialmente en medio de diferenciación ósea sin b-glicerofosfato (MCDO) para comenzar el proceso de diferenciación. Cuando las células alcanzaron la confluencia esperada se adicionó medio de diferenciación ósea con b-glicerofosfato $(\mathrm{MCDO}+\mathrm{b})$ para inducir la deposición de sales minerales. A las tres semanas se realizó Tinción de von Kossa (Solución De Nitrato De Plata, Ref. HT102-5 SIGMA - ALDRICH Steinheim, Alemania) y Fosfatasa Alcalina (Kit fosfatasa alcalina Ref. 86 SIGMA - ALDRICH Steinheim, Alemania). Como control se utilizaron CMMHs cultivadas en medio DMEM sin la aplicación del medio de diferenciación.

\section{Aplicación de la carga mecánica}

Las CMMHs se estimularon con un mecanotransductor que genera y aplica fuerzas tensionales uniaxiales cíclicas con un área de apoyo sobre los frascos de cul- tivo celular. Para esto se cultivaron $5 \times 10^{5} \mathrm{CMMHs}$ en frascos de cultivo de $75 \mathrm{~cm}^{2}$ en un área delimitada. Las células fueron sometidas a estimulación mecánica de $500,1000,1500$ y $2000 \mu \varepsilon$ con una intensidad de 9 ciclos/minuto por 3 horas durante 4 días consecutivos. Cada ensayo se realizó por triplicado. (El sistema de aplicación de fuerzas a nivel de celular, se encuentra actualmente en proceso de obtención de patente)

\section{Evaluación de expresión génica por la técnica cuantitativa de reacción en cadena de la Polimerasa (qPCR)}

La técnica cuantitativa de reacción en cadena de la Polimerasa (qPCR), también conocida como técnica de PCR en "tiempo real", se desarrolló utilizando SYBR Green para detectar la expresión de los genes Col-I, OC, ALP y factores de transcripción Runx2 y Sox9 utilizando como housekeeping o gen normalizador TBBP. Después de la carga mecánica, se aisló el RNA total de las CMMHs y se retrotranscribió a DNAc utilizando el kit Super ScriptTM II First-Strand Synthesis System (Invitrogen, Carlsbad, CA) de acuerdo con las instrucciones del fabricante. Las secuencias de los cebadores o primers se muestran en la tabla 1. La PCR cuantitativa se realizó utilizando el Kit DNA LightCycler ${ }^{\circledR}$ SYBR Green I (Roche, Mannheim, Germany). Las reacciones se realizaron en un volumen de $10 \mathrm{uL}$ y la lectura en el equipo LightCycler 480 (Roche, Mannheim, Germany). Cada reacción de PCR en tiempo real incluyó: 1 XSYBR Green, I Master Mix, 0,5 mM de cada cebador especifico, $2.0 \mu \mathrm{L}$ de cDNA y agua grado PCR.

La expresión de los genes se calculó por cuantificación relativa utilizando el método de doble delta $\mathrm{CT} ; 2^{-\Delta \Delta \mathrm{C}} \mathrm{T}$ $=\left(\mathrm{CT}_{\text {gen blanco }}-\mathrm{CT}_{\mathrm{TBBP}}\right)_{\text {control }}-\left(\mathrm{CT}_{\text {gen blanco }}-\mathrm{CT}_{\mathrm{TBBP}}\right)_{\text {muestra; }}$ Según Livak y Schmittgenun valor de $2^{-\Delta \Delta C T}>2$ se considera aumento en la expresión relativa de cada gen y factor de transcripción $(16,17)$.

\section{Resultados}

Potencial de diferenciación osteogénica de las CMMHs

Las CMMHs obtenidas por aspirado de médula ósea fueron positivas para la actividad de Fosfatasa Alcalina y Tinción de von Kossa después de tres semanas de exposición al medio completo de diferenciación osteogénica suplementado con $\beta$-glicerofosfato (Figura 1). 


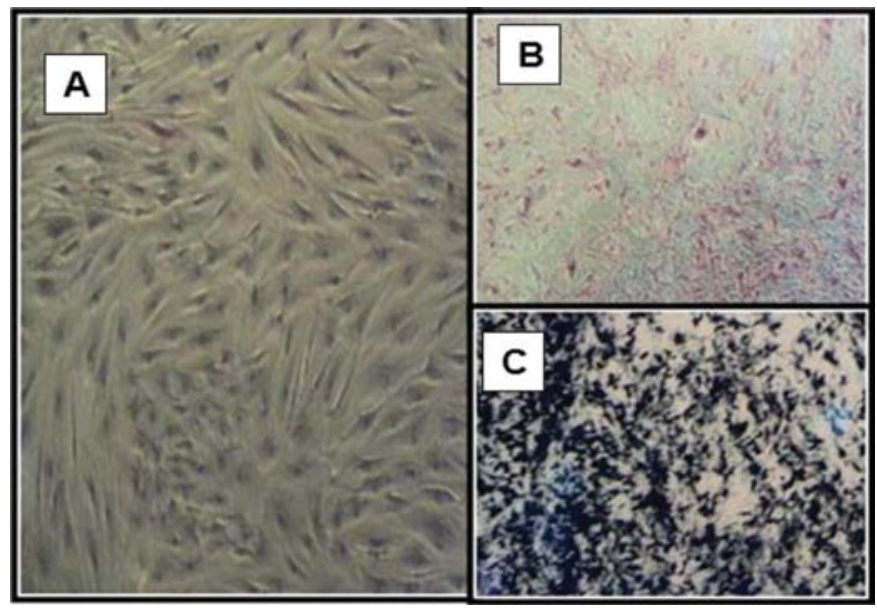

Figura 1. Potencial de diferenciación de las CMMHs, A. Control Negativo, B. CMMHs positivas para fosfatasa alcalina, C. CMMHs positivas para Tinción de von Kossa.

\section{Activación transcripcional de genes por qPCR}

La aplicación de carga mecánica a las CMMHs produce un efecto no lineal sobre la expresión relativa de los genes ALP, OC y Col1. En efecto, la expresión presenta un máximo en la expresión relativa de ALP (91,8 veces) y OC (16,7 veces) con un estímulo de $1000 \mu \varepsilon$. Estímulos menores y mayores produjeron incrementos menores en la expresión relativa de estos genes. (Tabla 2). Un efecto similar se observa con Col 1, pero en este caso la expresión máxima se da con una carga de 500 $\mu \varepsilon$ (4,7 veces). (Figuras 2E, $2 \mathrm{D}$ y $2 \mathrm{C}$ ). Por otro lado, se observó disminución en la expresión de los factores de transcripción Runx2 y Sox 9 con todas las cargas evaluadas con respecto al grupo control sin estimulación (Figura 2A y 2B).

\section{Discusión de Resultados}

En el presente estudio se evaluó el efecto del estímulo mecánico de 500, 1000, 1500 y $2000 \mu \varepsilon$ sobre la diferenciación in vitro de células madre mesenquimales obtenidas de médula ósea humana. Se encontró aumento en la expresión de los marcadores osteogénicos ALP, OC y Col1; siendo mayor en las células con estimulación mecánica que en las no estimuladas de grupo control. Estos resultados sugieren que el estímulo mecánico indujo la diferenciación de las $\mathrm{CMMHs}$ a osteoblastos lo cual se evidenció por la sobreexpresión de ALP y Col 1, Figura 3. La expresión de estos genes es regulada principalmente por el factor de transcripción Runx2, el cual se sobre-expresa en la etapa preosteoblástica y precondroblástica, dando inicio a la cascada de diferenciación a tejido óseo. Una vez determinado el linaje, la expresión de Runx2 establece el estado de maduración de los precursores celulares. Es importante destacar que la expresión de este factor de transcripción disminuye en etapas posteriores del proceso de diferenciación celular, como en efecto parece ocurrir en estos experimentos.

En la diferenciación osteogénica, el aumento en la actividad de ALP compromete las células a diferenciarse hacia el linaje osteoblástico (18). Simultáneamente, aunque en la literatura se ha descrito el aumento en la expresión de Runx 2 a 12 horas de estímulo mecánico, en esta prueba, en la cual las CMMHs se estimularon durante 4 días, la expresión de Runx2 se mantuvo disminuida con las cargas aplicadas; posiblemente por el estado de "determinación" de las células en cultivo. A este respecto, varios autores han descrito que la carga mecánica influencia la diferenciación de precursores celulares por incrementar la expresión del factor de transcripción Runx2 el cual es requerido para la inducción de la mayoría de genes necesarios para la síntesis de matriz ósea extracelular (19). Después de la aplicación de un estímulo mecánico in vivo e in vitro, se observa sobre-regulación en la expresión de Runx2 en respuesta a la aplicación de carga mecánica $(20,21)$. Posteriormente, durante la diferenciación, los osteoblastos expresan un patrón de genes característico (22) incluyendo Col1, el cual se expresa al inicio de la diferenciación osteoblástica durante la fase de proliferación, y OC, que es sobreregulado en estados tardíos de la diferenciación a osteoblastos (23). 


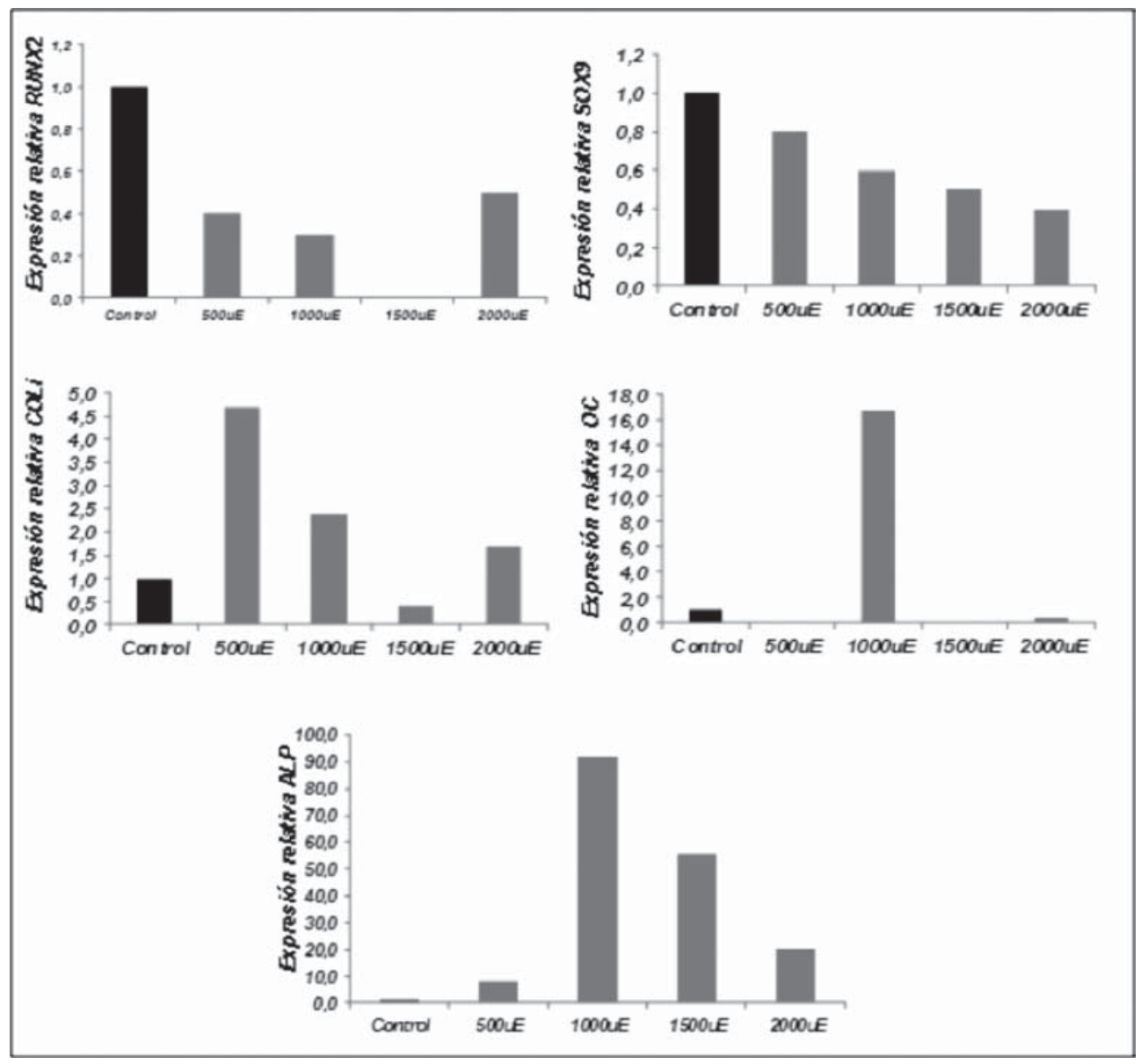

Figura 2. Expresión de los genes A.Runx2, B. Sox9, C. Col 1, D. OC y E. ALP. Se observa poca expresión de Runx2 y Sox9, aumento en la expresión de ALP y Col 1, y de OC a $1000 \mu \varepsilon$

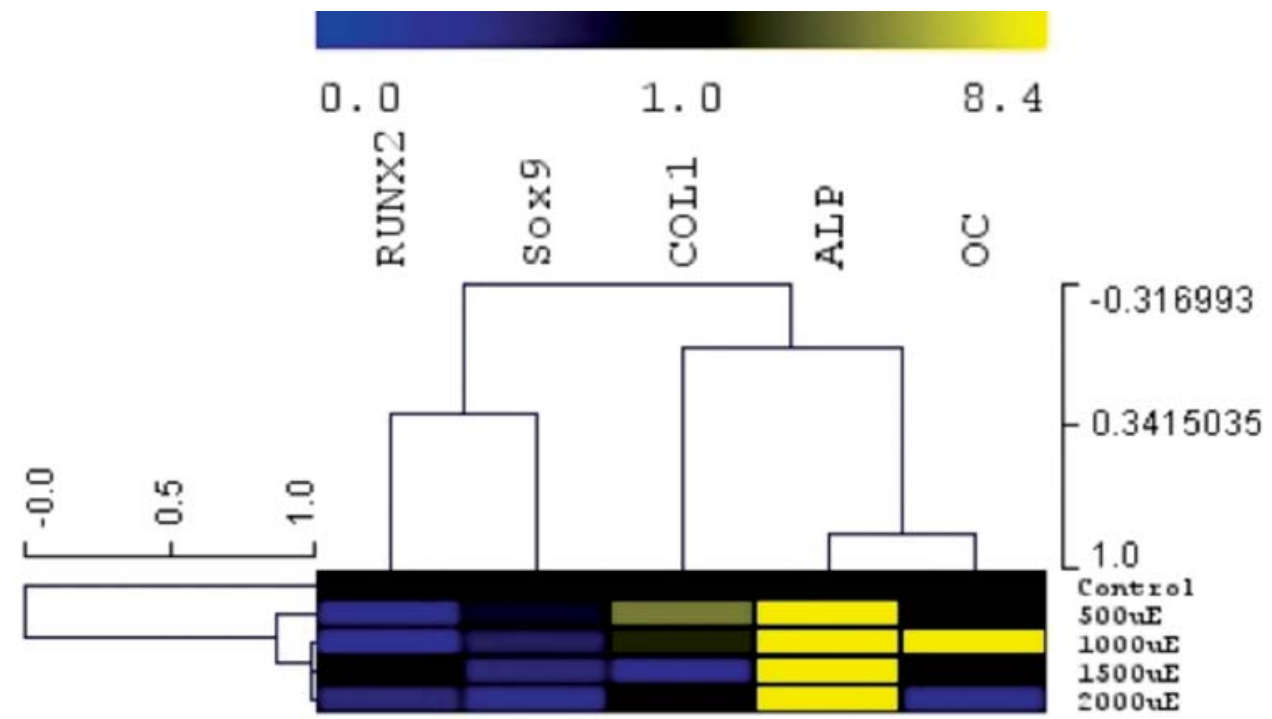

Figura 3. Mapa de calor de agrupaciones jerárquicas de la expresión de los factores de transcripción Runx 2 y Sox 9 y de los genes Col 1, OC y ALP frente a diferentes estímulos mecánicos. 
Tabla 1. Secuencias de Oligonucleótidos usados en $q P C R$

\begin{tabular}{|c|l|c|c|c|}
\hline GEN & \multicolumn{1}{|c|}{ FORWARD } & REVERSE & PRODUCTO & $\begin{array}{c}\text { CÓDIGO } \\
\text { DE BÚSQUEDA }\end{array}$ \\
\hline Runx2 & 5'-catctaatgacaccaccaggc-3' & 5'-gcctacaaaggtgggtttga-3' & $168 \mathrm{pb}$ & NM001015051.3 \\
\hline Sox9 & 5'-gctgggaaacatttgcactct-3' & 5'-ctgagaggcacaggtgacag-3' & $216 \mathrm{pb}$ & NM000346.3 \\
\hline COL1 & 5'-tgacctcaagatgtgccact-3' & 5'-accagacatgcctcttgtcc-3' & $197 \mathrm{pb}$ & NM000088.3 \\
\hline OC & 5'-cctcacactcctcgccctat-3' & 5'-tcccagccattgatacaggt-3' & $166 \mathrm{pb}$ & NM199173.4 \\
\hline ALP & 5'- tcagaagctcaacaccaacg-3' & 5'-gtcagggacctgggcatt-3' & $199 \mathrm{pb}$ & NM000478.4 \\
\hline TBBP & 5'-tgcacaggagccaagagtgaa -3' & 5'-cacatcacagctccccacca -3' & $131 \mathrm{pb}$ & NM003194.3 \\
\hline
\end{tabular}

Tabla 2. Valor de de 2- $\Delta \Delta C T$ para cada uno de los factores de transcripción y genes evaluados. Un valor de 2- $\Delta \Delta C T>2$ se considera aumento en la expresión relativa de los genes. La carga de $1000 \mu \varepsilon$ demostró ser efectiva en la sobre-expresión de Col 1, ALP y OC.

\begin{tabular}{|c|c|c|c|c|c|}
\hline Estímulo & Runx2 & Sox 9 & Col 1 & ALP & Osteocalcina \\
\hline Control & 1,0 & 1,0 & 1,0 & 1,0 & 1,0 \\
\hline $500 \mathrm{uE}$ & 0,4 & 0,8 & 4,7 & 8,4 & 0 \\
\hline $1000 \mathrm{uE}$ & 0,3 & 0,6 & 2,4 & 91,8 & 16,7 \\
\hline $1500 \mathrm{uE}$ & 0 & 0,5 & 0,4 & 56,1 & 0 \\
\hline $2000 \mathrm{uE}$ & 0,5 & 0,4 & 1,7 & 20,4 & 0,4 \\
\hline
\end{tabular}

El aumento observado en los niveles de expresión de los marcadores osteogénicos; ALP, OC y COL 1 durante la estimulación mecánica de las $\mathrm{CMMHs}$ con el estímulo de $1000 \mu \varepsilon$, refleja los tres estadios de diferenciación osteoblástica descritos. En este sentido, los preosteoblastos después de terminar la etapa de proliferación, secretan componentes de matriz extracelular, como es el caso de Col1, para continuar después con la fase de mineralización de la matriz extracelular. Durante esta etapa ALP se sobre-expresa y el estado de la célula cambia de proliferación a formación de matriz extracelular. Cuando la célula inicia el proceso de síntesis de matriz extracelular, se inicia la mineralización de la matriz procesos mediado por la expresión del gen de OC, implicado en la unión de los iones Calcio $\left(\mathrm{Ca}^{++)} \mathrm{e}\right.$ hidroxiapatita $\left(\mathrm{Ca}_{10}\left(\mathrm{PO}_{4}\right)_{6}(\mathrm{OH})_{2}\right)$ durante este proceso de mineralización ósea (24).

Como confirmación de lo anterior, se evidenció que el estímulo mecánico modula la respuesta de las $\mathrm{CMMHs}$ aumentando la expresión de ALP, OC y COL1, induciendo el proceso de mineralización y formación de tejido óseo $(25,26)$.

Adicionalmente, los estímulos mecánicos de 500, 1000,1500 y $2000 \mu \varepsilon$ aplicados a las CMMHs indu- jeron la expresión de gen de ALP. ALP, se expresa en estadios tempranos de diferenciación y su expresión se mantiene hasta las etapas de mineralización y remodelado óseo; desempeñando un papel importante en la mineralización de la matriz extracelular (27). La función de ALP es hidrolizar el fósforo orgánico y liberar fósforo inorgánico para la formación de la hidroxiapatita del hueso. Su actividad puede ser indicador del inicio de la etapa de diferenciación, mineralización de la matriz extracelular y remodelado de tejido óseo (28). Varios estudios han demostrado que ALP actúa como marcador temprano de actividad y diferenciación celular y sus niveles pueden ser regulados en respuesta a la aplicación de la fuerza mecánica (29).

A pesar haberse observado sobreexpresión de ALP con todas las cargas evaluadas, los estímulos de 1000 y $1500 \mu \varepsilon$ indujeron la mayor expresión de este gen: 91.8 y 56.1 veces respectivamente. Sin embargo, el aumento de la carga mecánica a $2000 \mu \varepsilon$, y la aplicación de cargas mecánicas inferiores de $500 \mu \varepsilon$ tiene un menor efecto en la expresión de ALP: 20.4 y 8.4 veces respectivamente, sugiriendo que el efecto del estimulo mecánico sobre las $\mathrm{CMMHs}$ depende de la magnitud de la carga mecánica aplicada, como lo descrito por Koike et al. en el 2005 (30). OC es 
un marcador de diferenciación del pre-osteoblasto al osteoblasto y aparece cuando se inicia la mineralización ósea. Su expresión está altamente restringida al tejido óseo, específicamente a las regiones destinadas a la mineralización (31). No sólo es sintetizada por los osteoblastos maduros, sino también por los odontoblastos y condrocitos hipertróficos (32) y participa en los procesos de regeneración ósea. Se piensa que interactúa directamente con la hidroxiapatita a través del residuo Gla (33). Es un marcador tardío de la diferenciación y adquiere sus máximos niveles de expresión durante el período de mineralización (34).

El estímulo de $1000 \mu \varepsilon$, fue el único estímulo que indujo la expresión de OC: 16.7 veces, sugiriendo que OC marca la transición de la maduración de la matriz dando paso al proceso de mineralización (35-37).

La OC es una proteína de matriz extracelular que funciona como modulador de la mineralización de la matriz, donde Col I y BSP funcionan como andamiaje de mineralización y formación de hidroxiapatita (38). Esta observación sugiere que las CMMHs se pueden diferenciar a células osteoblásticas in vitro, con alto potencial de diferenciación para expresar características de linaje osteogénico y actividad después de la expresión de Runx2 como se ha visto en células madre embrionarias murinas (39), células estromales de médula ósea (40) y células madre derivadas de tejido adiposo (41). La sobre-regulación de OC: 16,7 veces con un estímulo de $1000 \mu \varepsilon$, indica que a las primeras horas de estímulo mecánico Runx2 tuvo que sobreexpresarse para inducir la diferenciación osteogénica terminal de las CMMHs.

El colágeno tipo I se expresa de forma temprana en osteoprogenitores y en tejidos que se encuentran en proceso de remodelacióny refleja la actividad de formación de tejido óseo. Los estímulos de 500 y $1000 \mu \varepsilon$ aumentaron la expresión de Col 1: 4,7 y 2,4 veces respectivamente, como lo observado por Jones et al., (42) después del estímulo mecánico en osteoblastos bovinos con bajos estímulos, en los cuales hay aumento en la proliferación celular. Los resultados anteriores demuestran que la carga mecánica es necesaria para la diferenciación de la $\mathrm{CMMH}$ al linaje osteoblástico. Dado lo anterior, la modulación de la carga mecánica en tipo, dirección, magnitud, frecuencia y duración será de gran importancia en procesos de apoyo al área de clínica con modelos de intervención directa sobre pacientes y en modelos de intervención indirecta a través de procesos de desarrollo de ingeniería de tejidos.

\section{Agradecimientos}

A la Universidad Militar Nueva Granada, a la Pontificia Universidad Javeriana, a la Universidad Nacional de Colombia, al Hospital Militar Central y al Instituto, Stem Medicina Regenerativa, por su apoyo para la exitosa ejecución de este proyecto.

\section{Conflicto de interés}

Los autores expresan que no presentan ningún conflicto de interés en la publicación de los resultados de esta investigación.

\section{Referencias bibliográficas}

1. Kushida N, Kabuyama Y, Yamaguchi O, Homma Y. Essential role for extracellular $\mathrm{Ca}(2 \mathrm{p})$ in JNK activation by mechanical stretch in bladder smooth muscle cells. Am J Physiol Cell Physiol. 2001; 281: 1165-1172.

2. You J, Reilly GC, Zhen X, Yellowley CE, Chen Q, Donahue HJ, Jacobs CR. Osteopontin gene regulation by oscillatory fluid flow via intracellular calcium mobilization and activation of mitogen-activated protein kinase in MC3T3-E1 osteoblasts. J Biol Chem. 2001; 276: 13365-13371

3. Jessop HL, Rawlinson SC, Pitsillides AA, Lanyon LE. Mechanical strain and fluid movement both activate extracellular regulated kinase (ERK) in osteoblast-like cells but via different signaling pathways. Bone. 2002; 31:186-194.

4. Weyts FA, Li YS, van Leeuwen J, Weinans H, Chien S. ERK activation and alpha $v$ beta 3 integrin signaling through Shc recruitment in response to mechanical stimulation in human osteoblasts. J Cell Biochem. 2002; 87: 85-92.

5. Geng WD, Boskovic G, Fultz ME, Li C, Niles RM, Ohno S, Wright GL. Regulation of expression and activity of four PKC isozymes in confluent and mechanically stimulated UMR-108 osteoblastic cells. J Cell Physiol. 2001; 189: 216-228.

6. Danciu TE, Adam RM, Naruse K, Freeman MR, Hauschka PV. 2003. Calcium regulates the PI3K-Akt pathway in stretched osteoblasts. FEBS Lett. 2003; 536: 193-197.

7. Ziros PG, Gil AP, Georgakopoulos T, Habeos I, Kletsas D, Basdra EK, Papavassiliou AG. The bone-specific transcriptional regulator Cbfa1 is a target of mechanical signals in osteoblastic cells. J Biol Chem. 2002; 277: 23934-23941.

8. Franceschi RT, Xiao G, Jiang D, Gopalakrishnan R, Yang S, Reith E. Multiple signaling pathways converge on the Cbfa1/ Runx2 transcription factor to regulate osteoblast differentiation. Connect Tissue Res. 2003; 44: 109-116.

9. Lian JB, Javed A, Zaidi SK, Lengner C, Montecino M, van Wijnen AJ, Stein JL, Stein GS. Regulatory controls for osteoblast growth and differentiation: Role of Runx/ Cbfa/AML factors. Crit Rev Eukaryot Gene Expr. 2004; 14: 1-41.

10. Wang FS, Wang CJ, Sheen-Chen SM, Kuo YR, Chen RF, Yang KD. Superoxide mediates shock wave induction of ERK-dependent osteogenic transcription factor (CBFA1) and mesenchymal cell differentiation toward osteoprogenitors. J Biol Chem. 2002; 277: 10931-10937. 
11. Ontiveros C, McCabe LR. Simulated microgravity suppresses osteoblast phenotype, Runx2 levels and AP-1 transactivation. J Cell Biochem- 2003; 88: 427-437.

12. Meyers VE, Zayzafoon M, Gonda SR, Gathings WE, McDonald JM. Modeled microgravity disrupts collagen I/integrin signaling during osteoblastic differentiation of human mesenchymal stem cells. J Cell Biochem. 2004; 93: 697-707.

13. Liedert A, Kaspar D, Blakytny R, Claes L, Ignatius A. Signal transduction pathways involved in mechanotransduction in bone cells. BiochemBiophys Res Commun. 2006; 349(1): 1-5.

14. Boutahar N, Guignandon A, Vico L, Lafage-Proust MH. Mechanical strain on osteoblasts activates autophosphorylation of focal adhesion kinase and proline-rich tyrosine kinase 2 tyrosine sites involved in ERK activation. J Biol Chem. 2004 279: 30588-30599.

15. Katz S, Boland R, Santillan G. Modulation of ERK $1 / 2$ and $p 38$ MAPK signaling pathways by ATP in osteoblasts: Involvement of mechanical stress-activated calcium influx, PKC and Src activation. Int J Biochem Cell Biol. 2006; 38: 2082-2091.

16. Livak KJ, Schmittgen TD. Analysis of relative gene expression data using real-time quantitative PCR and the 2 (-Delta Delta C(T)) Method. Methods. 2001; 25(4): 402-8

17. Chen $\mathrm{H}$, Lin $\mathrm{Y}$, Zhongfang L, Jun Y, Junjie Z, Xu D, et al. Detection of CCND1 amplification using laser capture microdissection coupled with real-time polymerase chain reaction in human esophageal squamous cell carcinoma, Cancer Gen. Cytogen. 2007; 175: 19e-25.

18. Somerman MJ, Archer SY, Imm GR, Foster RA. A comparative study of human periodontal ligament cells and gingival fibroblasts in vitro. J Dent Res 1988; 67: 66-70.

19. Ducy P, Zhang R, Geoffroy V, Ridall AL, Karsenty G. Osf2/ Cbfa1: A transcriptional activator of osteoblast differentiation. Cell. 1997; 89(5): 747-754.

20. Kawarizadeh A, Bourauel C, Gotz W, Jager A. Early responses of periodontal ligament cells to mechanical stimulus in vivo. J. Dent. Res. 2005; 84(10):902-906.

21. Ziros PG, Gil AP, Georgakopoulos T, Habeos I, Kletsas D, Basdra EK, et al. The bone-specific transcriptional regulator Cbfa1 is a target of mechanical signals in osteoblastic cells. J. Biol. Chem. 2002; 277(26): 23934-23941.

22. Caetano-Lopes J, Canhao H, Fonseca JE. Osteoblasts and bone formation. ActaReumatol. Port. 2007; 32(2): 103-110.

23. Kearney EM, Farrell E, Prendergast PJ, Campbell VA. Tensile Strain as a Regulator of Mesenchymal Stem Cell Osteogenesis. Ann Biomed Eng. 2010; 38(5): 1767-79.

24. Arpornmaeklong P, Brown SE, Wang Z, Krebsbach PH.Phenotypic characterization, osteoblastic differentiation, and bone regeneration capacity of human embryonic stem cell-derived mesenchymal stem cells. Stem Cells Dev. 2009; 18(7): 955-68.

25. Ali MM, Yoshizawa T, Ishibashi O, Matsuda A, Shimomura $\mathrm{J}$, Mera H, Nakashima K, Kawashima H. PIASx beta is a key regulator of osterix transcriptional activity and matrix mineralization in osteoblasts. J Cell Sci. 2007; 120: 2565-2573.

26. Lee HL, Yi TG, Woo KM, Ryoo HM, Kim GS, Baek JH. Msx2 mediates the inhibitory action of TNF- $\alpha$ on osteoblast differentiation. ExpMol Med. 2010; 42: 437-445.
27. M. Koike, H. Shimokawa, Z. Kanno, K. Ohya, K. Soma Effects of mechanicalstrain on proliferation and differentiation of bone marrow stromal cell line ST2J Bone Miner Metab. 2005; 23: 219-225.

28. J. Liu, T. Liu, Y. Zheng, Z. Zhao, Y. Liu, H. Cheng, S. Luo, Y. Chen Early responses of osteoblast-like cells to different mechanical signals through various signaling pathways. BiochemBiophy Res Commun.2006; 348: 1167-1173.

29. Kirkham GR, Cartmell SH. Genes and Proteins involved in the regulation of Osteogenesis. En: Ashammakhi N, Reis R, Chiellini E, editores. Topics in Tissue Engineering. 2007. Vol. 3.

30. Koike M, Shimokawa H, Kanno Z, Ohya K, Soma K.Effects of mechanical strain on proliferation and differentiation of bone marrow stromal cell line ST2.J Bone Miner Metab. 2005; 23(3): 219-25

31. Mundy G.R, Cytokines and growth factors in the regulation of bone remodeling. Journal of Bone and Mineral Research. 1993; 8(S2): S505-S510.

32. Nather A., Ong H.J.C., Aziz Z. Structure of Bone. En: Bone Grafts and Bone Substitutes: Basic Science And Clinical Applications. World Scientific. Aziz Nather Editorial. 2005; 3-17.

33. Kobayashi T, Kronenberg H. Minireview: transcriptional regulation in development of bone. Endocrinology. 2005; 146(3): 1012-7.

34. Ducy P, Desbois C, Boyce B, Pinero G, Story B, et al.. Increased bone formation in osteocalcin-deficient mice. Nature. 1996; 382(6590): 448-452

35. Hall, B. K, Miyake T. All for one and one for all: Condensations and the initiation of skeletal development. Bioessays. 2000 22(2): 138-147.

36. Owen, TA, Aronow M, Shalhoub V, Barone LM, Wilming L, Tassinari MS, et al. Progressive development of the rat osteoblast phenotype in vitro: Reciprocal relationships in expression of genes associated with osteoblast proliferationand differentiation during formation of the bone extracellular matrix. J. Cell. Physiol. 1990; 143(3): 420-430.

37. Saito Y, Yoshizawa T, Takizawa F, Ikegame M, Iahibashi $\mathrm{O}$, Okubo K, et al. A cell line with characteristics of the periodontal ligament fibroblasts is negatively regulated for mineralization and Runx2/Cbfa1/Osf2 activity, part of which can be overcome bybone morphogenetic protein-2. J Cell Sci. 2002; 115: 4191-4200

38. Tai G, Polak JM, Bishop AE, Christodoulou I, Buttery LD. Differentiation of osteoblasts from murine embryonic stem cells by overexpression of the transcription factor Osx. TissueEng. 2004; 10: 1456-1466

39. Tu Q, Valverde $P$, Chen J. Osx enhances proliferation and osteogenic potential of bone marrow stromal cells. BiochemBiophys Res Commun. 2006; 341: 1257-1265.

40. Wu L, Wu Y, Lin YF, Jing W, Nie X, Qiao J,et al. Osteogenic differentiation of adipose derived stem cells promoted by overexpression of Osx. Mol Cell Biochem. 2007; 301: 83-92.

41. Jones DB, Nolte H, Scholübbers JG, Turner E, Veltel D. Biochemical signal transduction of mechanical strain inosteoblastlike cells. Biomaterials. 1991; 12: 101-110. 